\title{
ANALYSIS OF AN ELEMENTARY REACTION MECHANISM FOR BENZENE OXIDATION IN SUPERCRITICAL WATER
}

\author{
JOANNA L. DINARO,${ }^{1}$ JACK B. HOWARD,${ }^{1}$ WILLIAM H. GREEN,${ }^{1}$ JEFFERSON W. TESTER ${ }^{1}$ \\ AND JOSEPH W. BOZZELLI ${ }^{2}$ \\ ${ }^{1}$ Department of Chemical Engineering and Energy Laboratory \\ Massachusetts Institute of Technology \\ Cambridge, MA 02139, USA \\ ${ }^{2}$ Chemistry and Chemical Engineering Department \\ New Jersey Institute of Technology \\ Newark, NJ 07102, USA
}

\begin{abstract}
A benzene supercritical water oxidation $(\mathrm{SCWO})$ mechanism, based on published low-pressure benzene combustion mechanisms and submechanisms describing the oxidation of key intermediates, was developed and analyzed to determine the controlling reactions under SCWO conditions of 750-860 K, 139-278 bar, and equivalence ratios from 0.5 to 2.5 . To adapt the combustion mechanisms to the lower temperature $(<975 \mathrm{~K})$ and higher pressure $(>220 \mathrm{bar})$ conditions, new reaction pathways were added, and quantum Rice-Ramsperger-Kassel theory was used to calculate the rate coefficients and, hence, product selectivities for pressure-dependent reactions. The most important difference between the benzene oxidation mechanism for supercritical water conditions and those for combustion conditions is reactions in supercritical water involving $\mathrm{C}_{6} \mathrm{H}_{5} \mathrm{OO}$ predicted to be formed by $\mathrm{C}_{6} \mathrm{H}_{5}$ reacting with $\mathrm{O}_{2}$. Through the adjustment of the rate coefficients of two thermal decomposition pathways of $\mathrm{C}_{6} \mathrm{H}_{5} \mathrm{OO}$, whose values are unknown, the model accurately predicts the measured benzene and phenol concentration profiles at $813 \mathrm{~K}, 246$ bar, stoichiometric oxygen, and 3-7 s residence time and reproduces the finding that the carbon dioxide concentration exceeds that of carbon monoxide at all reaction conditions and levels of benzene conversion. Comparison of the model predictions to benzene SCWO data measured at several different conditions reveals that the model qualitatively explains the trends of the data and gives good quantitative agreement without further adjustment of rate coefficients.
\end{abstract}

\section{Introduction}

Supercritical water oxidation (SCWO) is a remediation process for treating aqueous organic wastes. When organic compounds and oxygen are brought together in water well above its critical point of 221 bar and $647 \mathrm{~K}$, the organic is oxidized to carbon dioxide and water, heteroatoms are converted to their corresponding mineral acids and can be neutralized using a suitable base, and any nitrogen forms $\mathrm{N}_{2}$ or $\mathrm{N}_{2} \mathrm{O}$ [1]. The present working hypothesis maintains that SCWO proceeds by free-radical reactions and that the individual elementary reactions are similar to those which would take place in combustion at the temperature and pressure of SCWO. Furthermore, water, which serves as the reaction medium and participates in reactions both as a reactant and as a third-body collider, does not interfere with reaction events through solvation effects.

The free-radical reaction pathway hypothesis has received support by multiple attempts to model reactions using low-pressure combustion mechanisms adapted to SCWO conditions. Previous modeling efforts yielded kinetic mechanisms describing the oxidation of simple compounds such as hydrogen
[2-7], carbon monoxide $[3,5,6]$, methane $[5,6,8,9]$, methanol $[6,7,10-14]$, and phenol [15]. The model predictions have been compared, with varying degrees of success, to experimentally measured species concentration profiles.

An elementary reaction mechanism for benzene oxidation under supercritical water conditions was developed [16] based on a detailed kinetic mechanism for benzene oxidation under combustion conditions $[17,18]$. The present paper reports results obtained using this developed mechanism to identify reactions controlling benzene oxidation under supercritical water conditions. The model predictions are compared with benzene and phenol concentration profiles measured in our experimental investigation of benzene SCWO at 750-860 K and sub- to supercritical pressures (139-278 bar) under fuel-rich to fuel-lean conditions for reactor residence times of 3-7 s [19]. The details of these experiments are reported elsewhere [19], but briefly benzene SCWO was studied in an $11 \mathrm{~mL}$ Hastelloy C276 tubular plug-flow reactor. Temperature was controlled by immersing the reactor in a fluidized sand bath. Aqueous feed solutions of benzene and oxidant were 
pressurized, preheated, and delivered to the reactor. The reactor effluent was immediately quenched and analyzed for unreacted benzene and oxidation products. Upwards of $90 \%$ of the reacted benzene was accounted for in phenol, carbon monoxide, carbon dioxide, and methane.

The various mechanisms developed to model benzene combustion successfully predict the oxidation of benzene as well as many other stable and radical intermediates $[17,18,20-24]$. The main shortcomings of these models are their pronounced overpredictions of the concentrations of $\mathrm{C}_{6} \mathrm{H}_{5}, \mathrm{C}_{6} \mathrm{H}_{5} \mathrm{O}$, and $\mathrm{C}_{6} \mathrm{H}_{5} \mathrm{OH}$. Given that these species are the primary products of benzene oxidation, this inaccuracy is troubling. As noted by Chai and Pfefferle [25], the current benzene oxidation models, developed primarily for temperatures above $1600 \mathrm{~K}$ and fuel-rich conditions, are not usable outside of the temperature and stoichiometric conditions for which they were adjusted, and the understanding of the detailed oxidation mechanism is particularly poor at $900-1300$ $\mathrm{K}$ and fuel-lean conditions. Under SCWO conditions, new reaction pathways may be accessible due to the higher pressure, and thermal decomposition pathways with high activation barriers which play important roles at combustion conditions may be inaccessible due to the lower temperatures. Therefore, comparisons of the predictions of a current benzene combustion mechanism $[17,18]$ against our data for the SCWO of benzene will test the robustness of the mechanism while furthering the understanding of benzene oxidation.

\section{Adaptation of Benzene Oxidation Mechanisms from Combustion to Supercritical Water Conditions}

The most obvious modification necessary to make low-pressure combustion mechanisms suitable for SCWO conditions is adjustment of reaction rate coefficients for the effect of pressure. Unimolecular rate coefficients are well known to depend on pressure to a power which is unity in the low-pressure limit, zero in the high-pressure limit, and fractional in the intermediate-pressure or fall-off region. The transitions to the low- and high-pressure limits occur at reaction-specific pressures.

Recombination reactions exhibit the same pressure dependence as unimolecular reactions when only one reaction pathway is possible. When additional products can be formed by chemically activated pathways, a complex pressure and temperature dependence can result from the competition between the stabilization and the decomposition and/or isomerization pathways [26,27], and experimentally measured rate coefficients cannot be extrapolated directly to other temperatures and pressures. The computer programs CHEMACT [27] and
CHEMDIS [28,29] implement the bimolecular Quantum Rice Ramsperger Kassel (QRRK) analysis of Dean [26] and allow the estimation of the pressure and temperature dependence of the rate coefficients for such reactions. Westmoreland et al. [30] and Dean [26] discussed the governing bimolecular and unimolecular QRRK equations and compared predicted and measured rate coefficients. In the present study, two important chemically activated reactions, between $\mathrm{H}$ and $\mathrm{O}_{2}$ and between phenyl $\left(\mathrm{C}_{6} \mathrm{H}_{5}\right)$ and $\mathrm{O}_{2}$, were evaluated.

$$
\mathrm{H}+\mathrm{O}_{2} \leftrightarrow \mathrm{HO}_{2}^{*} \leftrightarrow \mathrm{OH}+\mathrm{O}
$$

The addition/elimination reaction between $\mathrm{H}$ and $\mathrm{O}_{2}$ is one of the most important chain-branching steps in low-pressure combustion. The addition/ elimination pathway proceeds through the formation of the activated intermediate $\mathrm{HO}_{2}^{*}$, which can be stabilized to $\mathrm{HO}_{2}$ or dissociate to $\mathrm{OH}$ and $\mathrm{O}$. The relative importance of the two pathways depends on pressure and temperature, with the $\mathrm{HO}_{2}$-forming pathway favored at higher pressures.

Cobos et al. [31] studied the recombination reaction forming $\mathrm{HO}_{2}$ at $298 \mathrm{~K}$ and $1-200$ bar and estimated the high-pressure rate coefficient for recombination by extrapolating measured fall-off curves. Westmoreland et al. [30] used this high-pressure rate coefficient in a bimolecular QRRK analysis of the reaction between $\mathrm{H}$ and $\mathrm{O}_{2}$. The rates of both the stabilization (to $\mathrm{HO}_{2}$ ) and addition/elimination (to $\mathrm{OH}$ and $\mathrm{O}$ ) pathways were successfully predicted over wide ranges of temperature and pressure.

A bimolecular QRRK analysis similar to that of Westmoreland et al., conducted using CHEMACT with rate coefficients from Cobos et al. [31] and Baulch et al. [32], predicted $\mathrm{HO}_{2}$ to be the primary product of the reaction between $\mathrm{H}$ and $\mathrm{O}_{2}$ at 246 bar and $813 \mathrm{~K}$ (for which conditions the most complete set of benzene concentration data are available [19]) with a rate coefficient close to the high-pressure limit [31]. Further calculations reveal excellent agreement between the predicted and measured rate coefficients for the recombination reaction in the high- [31] and low-pressure limit [32] and the addition/elimination pathway [32].

$$
\mathrm{C}_{6} \mathrm{H}_{5}+\mathrm{O}_{2} \leftrightarrow \text { Products }
$$

The identity and formation rate of products of the reaction between phenyl and oxygen are a focus of continuing study. In previous benzene oxidation mechanisms, the products were set to phenoxy $\left(\mathrm{C}_{6} \mathrm{H}_{5} \mathrm{O}\right)$ and $\mathrm{O}[17,18,20-23]$. A semiglobal pathway was also included in some of these mechanisms $[17,18,23]$ :

$$
\mathrm{C}_{6} \mathrm{H}_{5}+\mathrm{O}_{2} \leftrightarrow 2 \mathrm{CO}+\mathrm{C}_{2} \mathrm{H}_{2}+\mathrm{C}_{2} \mathrm{H}_{3}
$$

Frank et al. [33] studied the reaction of phenyl with $\mathrm{O}_{2}$ between 900 and $1800 \mathrm{~K}$ and 1.3 to 2.5 bar 
TABLE 1

Comparison of predicted and experimental rate constants at 2.3 bar for the overall reaction $\mathrm{C}_{6} \mathrm{H}_{5}+\mathrm{O}_{2} \Leftrightarrow \mathrm{C}_{6} \mathrm{H}_{5} \mathrm{O}+\mathrm{O}$

\begin{tabular}{lcc}
\hline$T(\mathrm{~K})$ & $\begin{array}{c}\text { Measured by } \\
\text { Frank et al. [33] }\end{array}$ & $\begin{array}{c}\text { Predicted } \\
\text { by QRRK }\end{array}$ \\
\hline 1000 & $1.2 \times 10^{12}$ & $1.6 \times 10^{12}$ \\
1100 & $1.6 \times 10^{12}$ & $2.0 \times 10^{12}$ \\
1200 & $2.0 \times 10^{12}$ & $2.2 \times 10^{12}$ \\
\hline
\end{tabular}

and proposed two sets of products: (1) $\mathrm{C}_{6} \mathrm{H}_{5} \mathrm{O}$ and $\mathrm{O}$ and (2) $p$-benzoquinone $\left(\mathrm{C}_{6} \mathrm{H}_{4} \mathrm{O}_{2}\right)$ and $\mathrm{H}$. The second of these overall addition/elimination pathways was necessary to explain their observation of fast initial $\mathrm{H}$ production. Rate coefficients were measured for both pathways and were included in a mechanism by Tan and Frank [24].

$\mathrm{Yu}$ and Lin [34] performed a direct study on the reaction between $\mathrm{C}_{6} \mathrm{H}_{5}$ and $\mathrm{O}_{2}$ at $297-500 \mathrm{~K}$ and 20-80 Torr. The overall reactions leading to $\mathrm{C}_{6} \mathrm{H}_{5} \mathrm{O}$ and $\mathrm{O}$ or $\mathrm{C}_{6} \mathrm{H}_{4} \mathrm{O}_{2}$ and $\mathrm{H}$ proceed first through the formation of an energized $\mathrm{C}_{6} \mathrm{H}_{5} \mathrm{OO}$ radical $\left(\mathrm{C}_{6} \mathrm{H}_{5} \mathrm{OO}^{*}\right)$, which can undergo stabilization, isomerization, and/or dissociation to new products. $\mathrm{Yu}$ and $\mathrm{Lin}$ measured the recombination rate coefficient for $\mathrm{C}_{6} \mathrm{H}_{5}+\mathrm{O}_{2}$ by monitoring $\mathrm{C}_{6} \mathrm{H}_{5} \mathrm{OO}$ formation and found it to be pressure independent under their conditions. The sole reaction product was $\mathrm{C}_{6} \mathrm{H}_{5} \mathrm{OO}$, consistent with their Rice-Ramsperger-KasselMarcus prediction that stabilization to $\mathrm{C}_{6} \mathrm{H}_{5} \mathrm{OO}$ dominates over addition/elimination to $\mathrm{C}_{6} \mathrm{H}_{5} \mathrm{O}$ and $\mathrm{O}$ or $\mathrm{C}_{6} \mathrm{H}_{4} \mathrm{O}_{2}$ and $\mathrm{H}$ below $1000 \mathrm{~K}$ and between 20 and 80 Torr.

Since the reaction between $\mathrm{C}_{6} \mathrm{H}_{5}$ and $\mathrm{O}_{2}$ proceeds through the formation of $\mathrm{C}_{6} \mathrm{H}_{5} \mathrm{OO}^{*}$, the rate coefficients for the addition/elimination pathways measured at the conditions of Frank et al. [33] or used in low-pressure mechanisms [17,18,20-24] are not applicable at SCWO conditions. CHEMDIS was used to calculate the rate coefficients for stabilization (to $\mathrm{C}_{6} \mathrm{H}_{5} \mathrm{OO}$ ) and addition/elimination (to $\mathrm{C}_{6} \mathrm{H}_{5} \mathrm{O}$ and $\mathrm{O}$ ). The high-pressure rate coefficient for $\mathrm{C}_{6} \mathrm{H}_{5} \mathrm{OO}$ formation was taken from $\mathrm{Yu}$ and $\mathrm{Lin}$ [34], and the high-pressure rate coefficient for dissociation of $\mathrm{C}_{6} \mathrm{H}_{5} \mathrm{OO} *$ to $\mathrm{C}_{6} \mathrm{H}_{5} \mathrm{O}$ and $\mathrm{O}$ was estimated from microscopic reversibility and assuming the reverse reaction has a pre-exponential factor for diffusion-controlled reactions $\left(A=10^{12} \mathrm{~cm}^{3} \mathrm{~mol}^{-1}\right.$ $\left.\mathrm{s}^{-1}\right)$ and no energy barrier $\left(E_{\mathrm{a}}=0\right)$. At $813 \mathrm{~K}$ and $246 \mathrm{bar}$, the calculated stabilization rate coefficient is two orders of magnitude larger than that for addition/elimination to $\mathrm{C}_{6} \mathrm{H}_{5} \mathrm{O}$ and $\mathrm{O}$. A comparison between the predicted and measured [33] rate coefficients for the addition/elimination pathway at 2.3 bar and from 1000 to $1200 \mathrm{~K}$ showed agreement to within $10 \%$ to $20 \%$ (Table 1), indicating that the estimated value of $k_{\infty}$ for $\mathrm{C}_{6} \mathrm{H}_{5} \mathrm{OO}^{*}$ dissociation to $\mathrm{C}_{6} \mathrm{H}_{5} \mathrm{O}$ and $\mathrm{O}$ may not be a source of significant error.

Since $\mathrm{C}_{6} \mathrm{H}_{5} \mathrm{OO}$ was predicted to be the main reaction product of $\mathrm{C}_{6} \mathrm{H}_{5}$ and $\mathrm{O}_{2}$, bimolecular and unimolecular reactions of $\mathrm{C}_{6} \mathrm{H}_{5} \mathrm{OO}$ were also incorporated into the benzene SCWO mechanism [16]. The rates of the unimolecular reaction were found to dominate at supercritical water conditions. The unimolecular decomposition reactions of $\mathrm{C}_{6} \mathrm{H}_{5} \mathrm{OO}$ tested in the SCWO mechanism are

$$
\begin{aligned}
& \mathrm{C}_{6} \mathrm{H}_{5} \mathrm{OO} \leftrightarrow \mathrm{C}_{6} \mathrm{H}_{5} \mathrm{O}+\mathrm{O} \\
& \mathrm{C}_{6} \mathrm{H}_{5} \mathrm{OO} \leftrightarrow \mathrm{C}_{6} \mathrm{H}_{4} \mathrm{O}_{2}+\mathrm{H} \\
& \mathrm{C}_{6} \mathrm{H}_{5} \mathrm{OO} \leftrightarrow \mathrm{C}_{5} \mathrm{H}_{5}+\mathrm{CO}_{2}
\end{aligned}
$$

The rate coefficient of reaction $\mathrm{R} 2$ was calculated using QRRK analysis and the reverse rate constant by microscopic reversibility. Inclusion of reactions R3 and R4 was necessary, as will be shown below, to gain agreement between the predicted and experimental benzene concentration profile. However, reactions $\mathrm{R} 3$ and $\mathrm{R} 4$ are not elementary reactions, and rate coefficients for these overall steps were chosen so as to affect the radical pool to give the best fit between the mechanism predictions and the benzene concentration profile measured at $813 \mathrm{~K}, 246$ bar, and residence times of 3-7 s. Their reverse rate coefficients were calculated by microscopic reversibility. Since the present rate coefficients for reactions $\mathrm{R} 3$ and $\mathrm{R} 4$ are semiempirical, any attempt to use them in other models should be pursued with caution. While the mechanisms by which reactions R3 and R4 take place have not been experimentally determined and likely involve never observed intermediates, theoretical calculations using density functional analysis show that reactions R3 and R4 involve one common isomerization path through a dioxetane cyclic intermediate. After this first isomerization, a path to $\mathrm{C}_{6} \mathrm{H}_{4} \mathrm{O}_{2}+\mathrm{H}$ is present. A second series (unzipping process) is also present, along with another isomerization series. The rate-controlling step involves a 3,2,0 bicyclic (four plus five member ring) tight transition state. $\mathrm{CO}_{2}$ results from the unimolecular decomposition of this bicyclic [35-37].

Justification for the inclusion of reaction R3 comes from the detection of $\mathrm{C}_{6} \mathrm{H}_{4} \mathrm{O}_{2}$ during benzene combustion at both fuel-rich and fuel-lean conditions at 900-1300 K [25], our observation of $\mathrm{C}_{6} \mathrm{H}_{4} \mathrm{O}_{2}$ in the oxidation of benzene under supercritical water conditions $[16,19]$, and the incorporation of the overall reaction of $\mathrm{C}_{6} \mathrm{H}_{5}$ and $\mathrm{O}_{2}$ to $\mathrm{C}_{6} \mathrm{H}_{4} \mathrm{O}_{2}$ and $\mathrm{H}$ in the benzene combustion mechanism of Tan and Frank [24]. Since the reaction between $\mathrm{C}_{6} \mathrm{H}_{5}$ and $\mathrm{O}_{2}$ predominantly forms $\mathrm{C}_{6} \mathrm{H}_{5} \mathrm{OO}$ at 246 bar and $813 \mathrm{~K}$, reaction $\mathrm{R} 3$ was used in place of the addition/elimination reaction suggested by Frank et al. [33] to 
account for $\mathrm{C}_{6} \mathrm{H}_{4} \mathrm{O}_{2}$ production. Further reactions of $\mathrm{C}_{6} \mathrm{H}_{4} \mathrm{O}_{2}$ were accounted for by incorporating a recent submechanism [38] by which $\mathrm{C}_{6} \mathrm{H}_{4} \mathrm{O}_{2}$ is fully oxidized.

Reaction R4 is included to explain the very early appearance of $\mathrm{CO}_{2}$ in benzene oxidation under supercritical water conditions [16]. The $\mathrm{CO}_{2}$ yields exceeded those of $\mathrm{CO}$ at all conditions studied and for all conversions of benzene. Observations of $\mathrm{CO}_{2}$ yields always exceeding those of $\mathrm{CO}$ were also reported in the SCWO of phenol $[15,39]$ and substituted phenols [40-43], leading to speculation of pathways for $\mathrm{CO}_{2}$ formation which do not involve CO. Additionally, in benzene combustion at 900 $1300 \mathrm{~K}$ and at 350 Torr, Chai and Pfefferle [25] measured high amounts of $\mathrm{CO}_{2}$ at low benzene conversions and postulated $\mathrm{CO}_{2}$ production by routes other than the reaction of $\mathrm{OH}$ and $\mathrm{CO}$. Carpenter [35], Barckholtz et al. [36] and our work [37] show that the reaction of $\mathrm{C}_{6} \mathrm{H}_{5}$ and $\mathrm{O}_{2}$ leads to formation of $\mathrm{C}_{5} \mathrm{H}_{5}$ and $\mathrm{CO}_{2}$. In the present study, since $\mathrm{C}_{6} \mathrm{H}_{5} \mathrm{OO}$ is the primary reaction product of $\mathrm{C}_{6} \mathrm{H}_{5}$ and $\mathrm{O}_{2}$ at 246 bar and $813 \mathrm{~K}$, reaction $\mathrm{R} 4$ was included in place of an addition/elimination reaction.

\section{Comparison of Model Predictions and Measurements of Benzene Oxidation under Supercritical Water Conditions}

The predictions of the benzene SCWO mechanism [16], developed by adapting the benzene combustion mechanism of Shandross et al. [17] and Shandross [18] for the present conditions (813 K, $246 \mathrm{bar}$, and fuel equivalence ratio, $\Phi$, of 1.0), are compared in Fig. 1 (solid line) against the experimental data (points). Also shown is the profile predicted by the original mechanism of Shandross et al. [17] and Shandross [18] (long-dashed line), which generally represents the predictions of low-pressure benzene combustion mechanisms at SCWO conditions. Dissociation reactions of $\mathrm{C}_{6} \mathrm{H}_{5} \mathrm{OO}$ to $\mathrm{C}_{6} \mathrm{H}_{4} \mathrm{O}_{2}$ and $\mathrm{H}$ and $\mathrm{C}_{5} \mathrm{H}_{5}$ and $\mathrm{CO}_{2}$ were necessary in the SCWO mechanism to improve the agreement between the predictions and the data. With their inclusion, the shape and position of the predicted benzene concentration profile agree with the experimental data. The absolute values of the rate coefficients of reactions $\mathrm{R} 3$ and $\mathrm{R} 4$ were found not to have significant effects on the model predictions as long as the ratio of $k_{\mathrm{f}, 4}$ to $k_{\mathrm{f}, 3}$ is equal to 0.4 . If this ratio is larger or smaller than 0.4 , the predicted benzene reaction rate is too slow or too fast, respectively. Without inclusion of reaction $\mathrm{R} 3$ or R4, the predicted benzene oxidation rate is too fast and the reaction delay is too small (short-dashed line). The induction time can be varied from 0 to a maximum of $\sim 1 \mathrm{~s}$ by changing the rate coefficient of reaction R3. The dashed-and-dotted line represents the

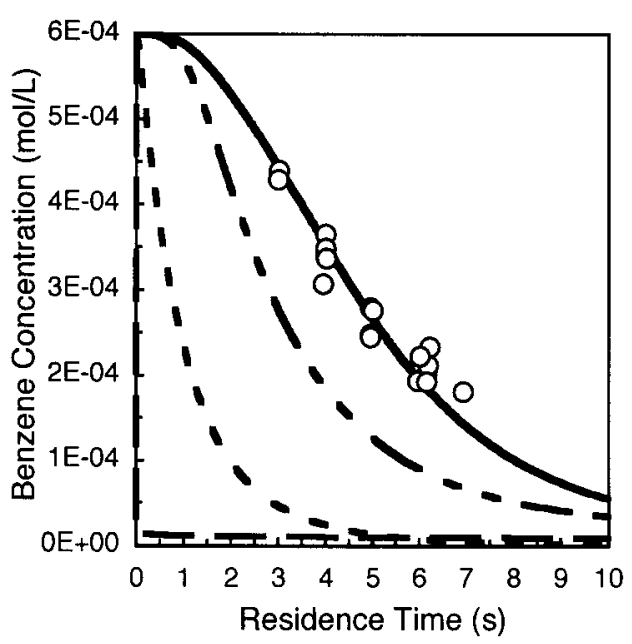

FIG. 1. Benzene concentration profiles predicted by the supercritical water benzene oxidation mechanism: $T=813$ $\mathrm{K} ; P=246$ bar; $\Phi=1.0 ;\left[\mathrm{C}_{6} \mathrm{H}_{6}\right]_{0}=0.6 \times 10^{-3} \mathrm{~mol} / \mathrm{L}$; (O) experimental data; - - mechanism of Shandross et al. [17] and Shandross [18]; - SCWO mechanism including reaction $\mathrm{R}_{3} \mathrm{C}_{6} \mathrm{H}_{5} \mathrm{OO} \leftrightarrow \mathrm{C}_{6} \mathrm{H}_{4} \mathrm{O}_{2}+\mathrm{H}$ with $k_{\mathrm{f}, 3}=$ $4.0 \times 10^{8} \mathrm{~s}^{-1}$ and reaction $\mathrm{R} 4 \mathrm{C}_{6} \mathrm{H}_{5} \mathrm{OO} \leftrightarrow \mathrm{C}_{5} \mathrm{H}_{5}+\mathrm{CO}_{2}$ with $k_{\mathrm{f}, 4}=1.6 \times 10^{8} \mathrm{~s}^{-1}$; - - - - - SCWO mechanism without reaction $\mathrm{R} 3$ or $\mathrm{R} 4$; - - - $\mathrm{SCWO}$ mechanism including only reaction $\mathrm{R} 3$ with $k_{\mathrm{f}, 3}=4.0 \times 10^{8} \mathrm{~s}^{-1}$.

slowest benzene oxidation rate that can be achieved through adjustment of $k_{\mathrm{f}, 3}$ (without including reaction R4).

The net rates of formation or destruction of key species by the individual reactions in the mechanism were calculated to determine the controlling reactions at $813 \mathrm{~K}$ and 246 bar with stoichiometric oxygen. By comparing the net rates of all reactions involving a single species, the primary destruction and formation pathways were determined.

Benzene was found to react almost exclusively by reactions R5 and R6:

$$
\begin{gathered}
\mathrm{C}_{6} \mathrm{H}_{6}+\mathrm{OH} \leftrightarrow \mathrm{C}_{6} \mathrm{H}_{5} \mathrm{OH}+\mathrm{H} \\
\mathrm{C}_{6} \mathrm{H}_{6}+\mathrm{OH} \leftrightarrow \mathrm{C}_{6} \mathrm{H}_{5}+\mathrm{H}_{2} \mathrm{O}
\end{gathered}
$$

with reaction $\mathrm{R} 6$ accounting for over $97 \%$ of the oxidation rate of benzene at $813 \mathrm{~K}$ and 246 bar. The rate coefficient used for reaction $\mathrm{R} 6$ [32] is the same as that used by Shandross et al. [17] and Shandross [18]. Although reaction R5 is recognized to proceed by a chemically activated pathway [44], given the relative unimportance of reaction $\mathrm{R} 5$ the rate coefficient used [45] is the same as that used by Shandross et al. [17] and Shandross [18]. The destruction of phenyl radical $\left(\mathrm{C}_{6} \mathrm{H}_{5}\right)$ formed by reaction $\mathrm{R} 6$ is completely accounted for by reaction R7: 


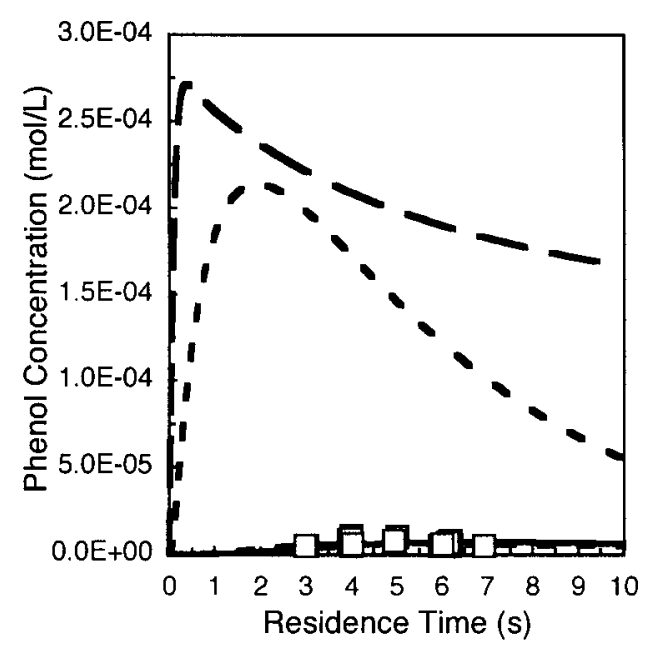

FIG. 2. Phenol concentration profiles predicted by the supercritical water benzene oxidation mechanism: $T=813$ $\mathrm{K} ; P=246$ bar: $\Phi=1.0 ;\left[\mathrm{C}_{6} \mathrm{H}_{6}\right]_{0}=0.6 \times 10^{-3} \mathrm{~mol} / \mathrm{L}$; ( $\square$ ) experimental data; - - mechanism of Shandross et al. [17] and Shandross [18]; — SCWO mechanism including reaction $\mathrm{R} 3 \mathrm{C}_{6} \mathrm{H}_{5} \mathrm{OO} \leftrightarrow \mathrm{C}_{6} \mathrm{H}_{4} \mathrm{O}_{2}+\mathrm{H}$ with $k_{\mathrm{f}, 3}$ $4.0 \times 10^{8} \mathrm{~s}^{-1}$ and reaction $\mathrm{R} 4 \mathrm{C}_{6} \mathrm{H}_{5} \mathrm{OO} \leftrightarrow \mathrm{C}_{5} \mathrm{H}_{5}+\mathrm{CO}_{2}$ with $k_{\mathrm{f}, 4}=1.6 \times 10^{8} \mathrm{~s}^{-1}$; - - - - SCWO mechanism without reaction $\mathrm{R} 3$ or $\mathrm{R} 4$; - - -- (almost hidden by - SCWO mechanism including only reaction $\mathrm{R} 3$ with $k_{\mathrm{f}, 3}=4.0 \times 10^{8} \mathrm{~s}^{-1}$.

$$
\mathrm{C}_{6} \mathrm{H}_{5}+\mathrm{O}_{2} \leftrightarrow \mathrm{C}_{6} \mathrm{H}_{5} \mathrm{OO}
$$

The fate of $\mathrm{C}_{6} \mathrm{H}_{5} \mathrm{OO}$ is the most critical unknown. Comparisons with the data suggest that the radicalforming, chain-branching loss channel to $\mathrm{C}_{6} \mathrm{H}_{5} \mathrm{O}$ and $\mathrm{O}$ (reaction $\mathrm{R} 2$ ) can only be a minor channel, and analysis of thermochemistry and the kinetics from the density functional analysis supports the ratio of 0.4 for $k_{\mathrm{f}, 4} / k_{\mathrm{f}, 3}$ under SCWO conditions [37].

The reactions and associated rate constants of cyclopentadienyl $\left(\mathrm{C}_{5} \mathrm{H}_{5}\right)$ and cyclopentadiene $\left(\mathrm{C}_{5} \mathrm{H}_{6}\right)$ in the Shandross mechanism were taken from the mechanism of Emdee et al. [21], in which the $\mathrm{C}_{5} \mathrm{H}_{5}$ submechanism was based on the outline presented by Brezinsky [46], and the abstraction of $\mathrm{H}$ from $\mathrm{C}_{5} \mathrm{H}_{6}$ by $\mathrm{HO}_{2}, \mathrm{OH}, \mathrm{H}$, and $\mathrm{O}$ was estimated from the analogous reactions with formaldehyde. In the SCWO-mechanism, we computed rate coefficients using CHEMDIS for the addition and combination reactions of $\mathrm{C}_{5} \mathrm{H}_{5}$ and $\mathrm{C}_{5} \mathrm{H}_{6}$ at 246 bar from 300 to $1000 \mathrm{~K}$ using the data presented in Zhong and Bozzelli $[47,48]$. Reactions with the highest rate coefficients at $813 \mathrm{~K}$ and 246 bar were included in the benzene SCWO mechanism, according to which $\mathrm{C}_{5} \mathrm{H}_{5}$ from reaction $\mathrm{R} 4$ reacts primarily by reaction $\mathrm{R} 8$ :

$$
\mathrm{C}_{5} \mathrm{H}_{5}+\mathrm{HO}_{2} \leftrightarrow \mathrm{C}_{5} \mathrm{H}_{5} \mathrm{O}+\mathrm{OH}
$$

$\mathrm{C}_{5} \mathrm{H}_{5} \mathrm{O}$ then undergoes ring-opening reactions, leading eventually to $\mathrm{CO}$ and $\mathrm{CO}_{2}$.

Since the oxidation of benzene proceeds mainly by reaction $\mathrm{R} 6$, the reaction delay (or induction time) and the subsequent rate of benzene reaction are determined by the rate of $\mathrm{OH}$ radical generation, which, in the present mechanism, is primarily by reaction $\mathrm{R} 8$.

If the global reactions $\mathrm{R} 3$ and $\mathrm{R} 4$ are not incorporated into the mechanism, reaction $\mathrm{R} 2$ is the dominant $\mathrm{C}_{6} \mathrm{H}_{5} \mathrm{OO}$ destruction channel. With $\mathrm{O}$ formed by reaction $\mathrm{R} 2$, excess $\mathrm{OH}$ is generated directly by reaction $R 9$

$$
\mathrm{O}+\mathrm{H}_{2} \mathrm{O} \leftrightarrow \mathrm{OH}+\mathrm{OH}
$$

and indirectly by the following series of reactions:

$$
\begin{gathered}
\mathrm{C}_{6} \mathrm{H}_{6}+\mathrm{O} \leftrightarrow \mathrm{C}_{6} \mathrm{H}_{5} \mathrm{O}+\mathrm{H} \\
\mathrm{H}+\mathrm{O}_{2} \leftrightarrow \mathrm{HO}_{2} \\
\mathrm{HO}_{2}+\mathrm{HO}_{2} \leftrightarrow \mathrm{H}_{2} \mathrm{O}_{2}+\mathrm{O}_{2} \\
\mathrm{H}_{2} \mathrm{O}_{2} \leftrightarrow \mathrm{OH}+\mathrm{OH}
\end{gathered}
$$

Reaction R6 proceeds much too quickly, and the present mechanism overpredicts the benzene oxidation rate.

As stated previously, the rate coefficients of reactions R3 and R4 were chosen to optimize modeldata agreement for the benzene concentration profile. Including reaction $\mathrm{R} 3$ with a higher rate constant than reaction $\mathrm{R} 2$ eliminates the rapid formation of $\mathrm{O}$ and the subsequent overproduction of $\mathrm{OH}$ by reaction R9. Since reaction $\mathrm{R} 3$ generates $\mathrm{H}$, $\mathrm{OH}$ formation proceeds through reactions $\mathrm{R} 11, \mathrm{R} 12$, and R13, and inclusion of reaction R3 alone cannot decrease the rate of benzene oxidation sufficiently to bring the model into agreement with the data. As discussed earlier, the reaction of $\mathrm{H}$ and $\mathrm{O}_{2}$ producing $\mathrm{OH}$ and $\mathrm{O}$ is not important at SCWO conditions. To gain model-data agreement, reaction $\mathrm{R} 4$ was included. The inclusion of reaction $\mathrm{R} 4$ slows the benzene oxidation rate, as $\mathrm{C}_{5} \mathrm{H}_{5}$ is relatively unreactive. Reaction R4 also provides a pathway for $\mathrm{CO}_{2}$ formation to account for the experimental observation that $\mathrm{CO}_{2}$ yields exceed those of $\mathrm{CO}$ for all measured residence times and reaction conditions [19]. Without reaction $\mathrm{R} 4$, the model incorrectly predicts that the $\mathrm{CO}_{2}$ concentration remains below that of $\mathrm{CO}$ for residence times less than $7 \mathrm{~s}$. Even with reaction R4, the model underpredicts the concentrations of $\mathrm{CO}$ and $\mathrm{CO}_{2}$, reflecting inadequate chemistry for further oxidation of intermediate species. A large fraction of carbon remains as $\mathrm{C}_{6} \mathrm{H}_{4} \mathrm{O}_{2}$, and $\mathrm{C}_{6} \mathrm{H}_{3} \mathrm{O}_{2}, \mathrm{C}_{5} \mathrm{H}_{5} \mathrm{O}$, $\mathrm{C}_{4} \mathrm{H}_{4}$, and $\mathrm{H}_{2} \mathrm{CCCCH}$ are also significant.

Figure 2 demonstrates that with inclusion of reactions $\mathrm{R} 3$ and $\mathrm{R} 4$, the predicted $\mathrm{C}_{6} \mathrm{H}_{5} \mathrm{OH}$ concentration profile agrees with the experimental data. 


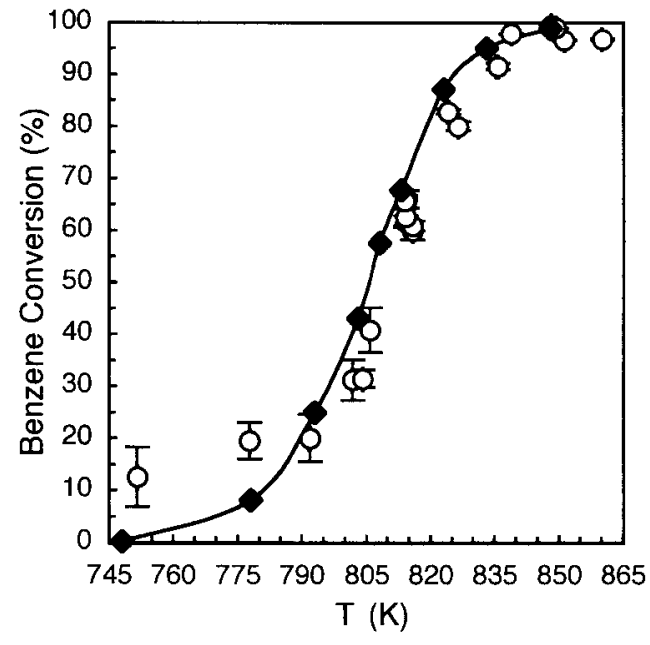

Fig. 3. Comparison of predicted (- - ) and measured (O) benzene conversions at various temperatures: $\tau=6.2$ s; $P=246$ bar; $\Phi=1.0 ;\left[\mathrm{C}_{6} \mathrm{H}_{6}\right]_{0}=0.6 \times 10^{-3} \mathrm{~mol} / \mathrm{L}$.

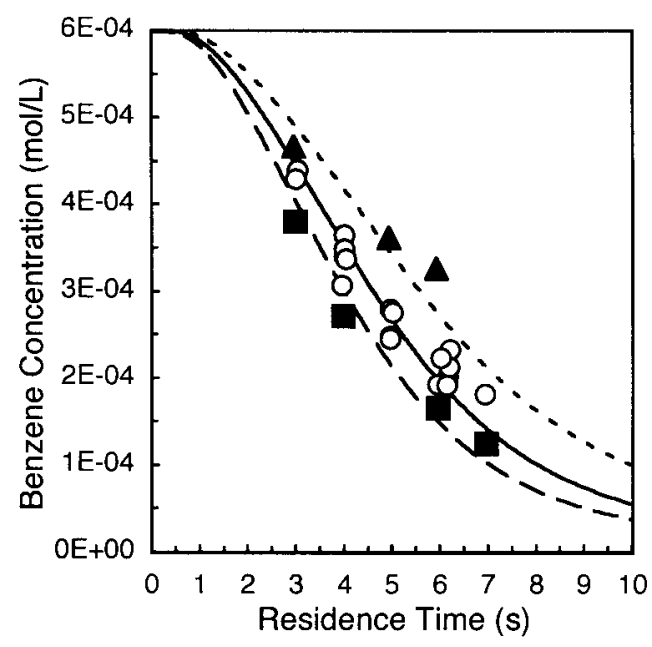

FIG. 4. Comparison of predicted (lines) and measured (symbols) benzene concentrations at three fuel equivalence $\operatorname{ratios}(\Phi):(\mathbf{\square},--) \Phi=0.5 ;(\bigcirc,-) \Phi=1.0 ;(\boldsymbol{\Delta}$ --- $) \Phi=2.5 . T=813 \mathrm{~K} ; P=246$ bar; $\left[\mathrm{C}_{6} \mathrm{H}_{6}\right]_{0}=0.6$ $\times 10^{-3} \mathrm{~mol} / \mathrm{L}$.

Without reactions $\mathrm{R} 3$ and $\mathrm{R} 4$, phenol is overpredicted by a factor of $\sim 100$. Phenol is initially formed by reaction $\mathrm{R} 5$, destroyed by reaction $\mathrm{R} 14$, and then reformed in reaction $\mathrm{R} 15$ in an equimolar exchange:

$$
\begin{aligned}
\mathrm{C}_{6} \mathrm{H}_{5} \mathrm{OH}+\mathrm{CH}_{2} \mathrm{CHCHCH} & \leftrightarrow \mathrm{C}_{6} \mathrm{H}_{5} \mathrm{O}+\mathrm{C}_{4} \mathrm{H}_{6} \\
\mathrm{C}_{6} \mathrm{H}_{5} \mathrm{O}+\mathrm{C}_{5} \mathrm{H}_{6} & \leftrightarrow \mathrm{C}_{6} \mathrm{H}_{5} \mathrm{OH}+\mathrm{C}_{5} \mathrm{H}_{5}
\end{aligned}
$$

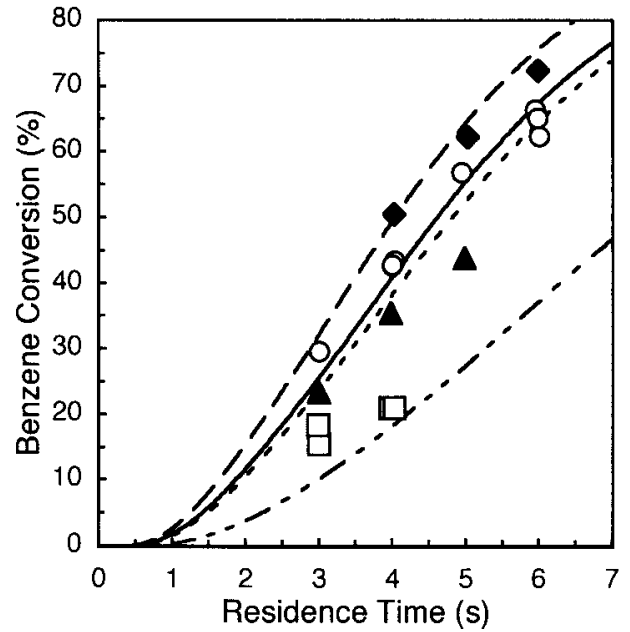

FIG. 5. Comparison of predicted (lines) and measured (symbols) benzene conversions at four water densities: $--) \rho=0.091 \mathrm{~g} / \mathrm{mL}(P=278 \mathrm{bar}) ;(\bigcirc, \longrightarrow) \rho=$ $0.079 \mathrm{~g} / \mathrm{mL}(P=246 \mathrm{bar}) ;(\boldsymbol{\Lambda},-\cdots) \rho=0.072 \mathrm{~g} / \mathrm{mL}(P$ $=228 \mathrm{bar}) ;(\square,---) \rho=0.041 \mathrm{~g} / \mathrm{mL}(P=139 \mathrm{bar})$. $T=813 \mathrm{~K} ;\left[\mathrm{C}_{6} \mathrm{H}_{6}\right]_{0}=0.6 \times 10^{-3} \mathrm{~mol} / \mathrm{L} ; \Phi=1.0$.

Rate coefficients for reactions R14 and R15 were kept at the values used by Shandross et al. [17] and Shandross [8]. Given that reactions $\mathrm{R} 14$ and R15 are the principal reactions involving both $\mathrm{C}_{6} \mathrm{H}_{5} \mathrm{O}$ and $\mathrm{C}_{6} \mathrm{H}_{5} \mathrm{OH}$ and that $\mathrm{C}_{6} \mathrm{H}_{5} \mathrm{OH}$ is minor compared with $\mathrm{C}_{6} \mathrm{H}_{5}$ as a benzene decomposition product, $\mathrm{C}_{6} \mathrm{H}_{5} \mathrm{O}$ is also not a key intermediate in the SCWO mechanism. Without reaction $\mathrm{R} 3$, excess $\mathrm{C}_{6} \mathrm{H}_{5} \mathrm{O}$ is formed by reaction $\mathrm{R} 2$, leading to the overprediction of $\mathrm{C}_{6} \mathrm{H}_{5} \mathrm{OH}$. With all reactions which lead to $\mathrm{C}_{6} \mathrm{H}_{5} \mathrm{OH}$ formation in the SCWO mechanism involving $\mathrm{C}_{6} \mathrm{H}_{5} \mathrm{O}$ with the exception of reaction $\mathrm{R} 5$, and given that reaction $\mathrm{R} 5$ is not competitive with reaction $\mathrm{R} 6$ at these conditions, agreement between the experimental and predicted $\mathrm{C}_{6} \mathrm{H}_{5} \mathrm{OH}$ concentrations indicates that $\mathrm{C}_{6} \mathrm{H}_{5} \mathrm{O}$ concentration is now properly predicted as long as the $\mathrm{C}_{6} \mathrm{H}_{5} \mathrm{O} / \mathrm{C}_{6} \mathrm{H}_{5} \mathrm{OH}$ chemistry is correctly represented.

To test the robustness of the mechanism, the model predictions were compared with benzene SCWO measurements over considerable ranges of reactor conditions [19]. No further adjustments were made to the mechanism. The rate constants of reactions $\mathrm{R} 3$ and $\mathrm{R} 4$ were treated as temperature independent. Benzene concentrations predicted by the model as a function of temperature at a given pressure, equivalence ratio, and residence time are compared with the experimental data in Fig. 3. Predicted benzene concentration profiles are compared with the data at equivalence ratios from 0.5 to 2.5 at a given temperature and pressure in Fig. 4 and over a range of water densities or pressures at a given 
temperature and equivalence ratio in Fig. 5. The good agreement seen between predictions and experimental data in all cases is especially encouraging in view of the ranges of conditions covered.

\section{Summary and Conclusions}

A benzene SCWO mechanism was developed using published benzene combustion mechanisms and submechanisms describing the oxidation of key intermediates. To adapt the benzene combustion mechanism to the lower temperatures and higher pressures of SCWO, new reaction pathways were added and QRRK theory was used to calculate the rate coefficients and predict reaction products for pressure-dependent reactions. The most important difference between the benzene oxidation mechanism for supercritical water conditions and those for combustion conditions is reactions in supercritical water involving $\mathrm{C}_{6} \mathrm{H}_{5} \mathrm{OO}$ predicted to be formed by $\mathrm{C}_{6} \mathrm{H}_{5}$ reacting with $\mathrm{O}_{2}$. By adjusting the rate constants of two proposed, global thermal decomposition reactions of $\mathrm{C}_{6} \mathrm{H}_{5} \mathrm{OO}$, the first forming $p$-benzoquinone and $\mathrm{H}$ and the second forming cyclopentadienyl and $\mathrm{CO}_{2}$, the model was fit to the benzene concentration profile measured during SCWO at $813 \mathrm{~K}, 246$ bar, and 3-7 s residence time with stoichiometric oxygen. The resulting mechanism accurately reproduces the experimental benzene and phenol concentration profiles at these conditions and predicts well the benzene concentration profiles under SCWO conditions ranging from 750 to $850 \mathrm{~K}, 139$ to $278 \mathrm{bar}$, and equivalence ratios from 0.5 to 2.5 .

\section{Acknowledgments}

We are grateful for helpful collaboration with K. A. Smith, W. A. Peters, the other members of the Massachusetts Institute of Technology SCWO research group, R. A. Shandross, H. Richter, and D. F. Kronholm and partial support from the URI (grant no. DAAL03-92-G-0177) and AASERT Programs (grant no. DAAH04-94-G-0145) of the Army Research Office, both under the supervision of R. Shaw, the SERDP grant under S. F. Rice at Sandia National Laboratories, and the National Institute of Environmental Health Sciences Superfund program.

\section{REFERENCES}

1. Killilea, W. R., and Swallow, K. C., J. Supercrit. Fluids 5:72 (1992).

2. Holgate, H. R., and Tester, J. W., Combust. Sci. Technol. 88:369 (1993).

3. Holgate, H. R., and Tester, J. W., J. Phys. Chem. 98:810 (1994).

4. Paterson, C., Breshears, D., and Foy, B., Combust. Sci. Technol. 89:411 (1993).
5. Dagaut, P., Daney de Marcillac, B., Tan, Y., Cathonnet, M., and Boettner, J.-C., J. Chim. Phys. 92:1124 (1995).

6. Brock, E. E., and Savage, P. E., AIChE J. 41:1874 (1995).

7. Alkam, M. K., Pai, V. M., Butler, P. B., and Pitz, W. J., Combust. Flame 106:110 (1996).

8. Webley, P. A., and Tester, J. W., Energy Fuels 5:411 (1991).

9. Savage, P. E., Yu, J. L., Stylski, N., and Brock, E. E., J. Supercrit. Fluids 12:141 (1998).

10. Webley, P. A., and Tester, J. W., in Supercritical Fluid Science and Technology (K. P. Johnston and J. M. L. Penninger, eds.), ACS Symposium Series 406, American Chemical Society, Washington, DC, 1989, p. 259.

11. Butler, P. B., Bergan, N. E., Bramlette, T. T., Pitz, W. J., and Westbrook, C. K., Oxidation of Hazardous Waste in Supercritical Water: A Comparison of Modeling and Experimental Results for Methanol Destruction, U.S. Department of Energy report DE91017097, 1991.

12. Schmitt, R. G., Butler, P. B., Westbrook, C. K., and Pitz, W. J., Destruction of Hazardous Waste in Supercritical Water, Part II: A Study of High Pressure Methanol Oxidation Kinetics, U.S. Department of Energy report DE92-008559, 1991.

13. Butler, P. B., Bergan, N. E., Bramlette, T. T., Westbrook, C. K., and Pitz, W. J., "Oxidation of Hazardous Waste in Supercritical Water, Part I: A Comparison of Modeling and Experimental Results for Methanol Destruction," U.S. Department of Energy report DE92008565, 1991.

14. Dagaut, P., Cathonnet, M., and Boettner, J.-C., J. Supercrit. Fluids 9:33 (1996).

15. Gopalan, S., and Savage, P. E., in Innovations in Supercritical Fluids (K. W. Hutchenson and N. R. Foster, eds.), ACS Symposium Series 608, American Chemical Society, Washington, DC, 1995, p. 217.

16. DiNaro, J. L., Ph.D. thesis, "Oxidation of Benzene in Supercritical Water: Experimental Measurements and Development of an Elementary Reaction Mechanism," Department of Chemical Engineering, Massachusetts Institute of Technology, Cambridge, MA, 1999.

17. Shandross, R. A., Longwell, J. P., and Howard, J. B., Proc. Combust. Inst. 26:711 (1996).

18. Shandross, R. A., Ph.D. thesis, "Expermental and Theoretical Study of Hydrogen and Benzene Destruction Chemistries," Department of Chemical Engineering, Massachusetts Institute of Technology, Cambridge, MA, 1996.

19. DiNaro, J. L., Tester, J. W., Swallow, K. C., and Howard, J. B., AIChE J. (2000).

20. Bittker, D. A., Combust. Sci. Technol. 79:49 (1991).

21. Emdee, J. L., Brezinsky, K., and Glassman, I., J. Phys. Chem. 96:2151 (1992).

22. Lindstedt, R. P., and Skevis, G., Combust. Flame 99:551 (1994).

23. Zhang, H.-Y., and McKinnon, J. T., Combust. Sci. Technol. 107:261 (1995). 
24. Tan, Y., and Frank, P., Proc. Combust. Inst. 26:677 (1996).

25. Chai, Y., and Pfefferle, L. D., Fuel 77:313 (1998).

26. Dean, A. M., J. Phys. Chem. 89:4600 (1985).

27. Dean, A. M., Bozzelli, J. W., and Ritter, E. R., Combust. Sci. Technol. 80:63 (1991).

28. Ing, W.-C., Ph.D. thesis, Department of Chemical Engineering, New Jersey Institute of Technology, Newark, NJ, 1995.

29. Chang, A. Y., Bozzelli, J. W., and Dean, A. M., Zeitschrift für Physikalische Chemie (2000).

30. Westmoreland, P. R., Howard, J. B., Longwell, J. P., and Dean, A. M., AIChE J. 32:1971 (1986).

31. Cobos, C. J., Hippler, H., and Troe, J., J. Phys. Chem. 89:342 (1985).

32. Baulch, D. L., Cobos, C. J., Cox, R. A., Esser, C., Frank, P., Just, T., Kerr, J. A., Pilling, M. J., Troe, J., Walker, R. W., and Warnatz, J., J. Phys. Chem. Ref. Data 21:411 (1992).

33. Frank, P., Herzler, J., Just, T., and Wahl, C., Proc. Combust. Inst. 25 (1994).

34. Yu, T., and Lin, M. C., J. Am. Chem. Soc. 116:9571 (1994).

35. Carpenter, B. K., J. Am. Chem. Soc. 115:9806 (1993).
36. Barckholtz, C., Fadden, M. J., and Hadad, C. M., J. Phys. Chem. 103:8108 (1999).

37. Sebbar N., Bockhorn, H., and Bozzelli, J. W., 28th Symposium (International) on Combustion, The Combustion Institute (2000) [Abstract only].

38. Alzueta, M. U., Oliva, M., and Glarborg, P., Int. J. Chem. Kin. 30:683 (1998).

39. Krajnc, M., and Levec, J., AIChE J. 42:1977 (1996).

40. Martino, C. J., Savage, P. E., and Kasiborski, J., Ind. Eng. Chem. Res. 34:1941 (1995).

41. Martino, C. J., and Savage, P. E., Ind. Eng. Chem. Res. 36:1391 (1997).

42. Martino, C. J., and Savage, P. E., Ind. Eng. Chem. Res. 38:1784 (1999).

43. Martino, C. J., and Savage, P. E., Ind. Eng. Chem. Res. 38:1775 (1999).

44. Lay, T. S., Bozzelli, J. W., and Seinfeld, J. H., J. Phys. Chem. 100:6543 (1996).

45. He, Y. Z., Mallard, W. G., and Tsang, W., J. Phys. Chem. 92:2196 (1988).

46. Brezinsky, K., Prog. Energy Combust. Sci. 12:1 (1986).

47. Zhong, X., and Bozzelli, J. W., Int. J. Chem. Kin. 29:893 (1997).

48. Zhong, X., and Bozzelli, J. W., J. Phys. Chem. 102:3537 (1998).

\section{COMMENTS}

Alexander Fridman, University of Illinois at Chicago, USA. Standard mechanisms of $\mathrm{C}_{6} \mathrm{H}_{6}$ oxidation in gas phase cannot be used for oxidation in supercritical water. When looking for special new oxidation channels in supercritical water, it would probably be important to take into consideration ion formation and following ion-molecular reactions like $\mathrm{H}_{3} \mathrm{O}^{+}+\mathrm{H}_{2} \mathrm{O} \rightarrow \mathrm{H}_{4} \mathrm{O}^{+}+\mathrm{OH}$, and so on, leading to $\mathrm{OH}$ formation. Such reactions in supercritical conditions can be important when working at higher temperature limits.

Author's Reply. Ionic reactions were not considered because the supercritical water environment at our conditions (475-600 C, 250 bar) does not support ionic species due to the low dielectric constant of water. In addition, typical ionization potentials are $200 \mathrm{kcal} / \mathrm{mol}$, whereas bond energies are about $100 \mathrm{kcal} / \mathrm{mol}$.

Horst Hippler, University of Karlsruhe, Germany. There is an alternative mechanism for the oxidation of benzene from atmospheric chemistry. $\mathrm{OH}$ radicals add to the benzene $\mathrm{OH}+\mathrm{C}_{6} \mathrm{H}_{6} \rightleftharpoons \mathrm{C}_{6} \mathrm{H}_{6} \mathrm{OH}$ (pre-equilibrium) and then $\mathrm{C}_{6} \mathrm{H}_{6} \mathrm{OH}$ reacts with $\mathrm{O}_{2}$. Could this be an alternative start into the SCWO of benzene? Additionally, the oxidation of $\mathrm{CO}$ with $\mathrm{OH}$ is strongly pressure dependent. The rate constant increases strongly with increasing pressure. Could this account for preferential finding $\mathrm{CO}_{2}$ and not $\mathrm{CO}$ ?

Author's Reply. The addition of $\mathrm{OH}$ to benzene to form a cyclohexadienyl-OH adduct followed by reaction with $\mathrm{O}_{2}$ is important in atmospheric chemistry (Lay et al., 1997), but not very important in combustion. The lifetime for dissociation of the cyclohexadienyl-OH adduct back to $\mathrm{OH}+$ benzene is not the order of $1 \mathrm{~s}$ at atmospheric temperature, but only about $3 \mu \mathrm{s}$ at SCWO temperatures. A more important reaction of the cyclohexadienyl-OH adduct at SCWO conditions is $\mathrm{H}$-atom elimination to phenol $+\mathrm{H}$. Here, reverse dissociation to benzene $+\mathrm{OH}$ is favored because of the higher entropy of $\mathrm{OH}+$ benzene relative to $\mathrm{H}+$ phenol and a slightly lower (less than $2 \mathrm{kcal} / \mathrm{mol}$ ) lower enthalpy for the dissociation. This reaction was taken into account by including the high pressure value of He et al. (1988) for the overall reaction.

The reaction of $\mathrm{CO}$ and $\mathrm{OH}$ proceeds through the formation of an activated HOCO intermediate. At high pressures, the stabilization pathway to HOCO dominates over the dissociation pathway to $\mathrm{CO}_{2}+\mathrm{H}$ (Fulle et al., 1996). Stabilized HOCO can then undergo reaction, including dissociation back to $\mathrm{CO}+\mathrm{OH}$ or to $\mathrm{CO}_{2}+\mathrm{H}$. As is the case with the cyclohexadienyl-OH adduct, reverse dissociation to products is favored over the $\mathrm{CO}_{2}+\mathrm{H}$ pathway. 